Article

\title{
Land Use Change in the Cross-Boundary Regions of a Metropolitan Area: A Case Study of Tongzhou-Wuqing-Langfang
}

\author{
Linlin Dai ${ }^{1}$, Zixin Zhan ${ }^{1}{ }^{\mathbb{D}}$, Yeshuo Shu ${ }^{2}$ and Xiao Rong ${ }^{3, *}$ \\ 1 College of Urban and Environmental Sciences, Peking University, Beijing 100871, China; \\ linlindai@pku.edu.cn (L.D.); zhanzixin@pku.edu.cn (Z.Z.) \\ 2 College of Architecture and Landscape, Peking University, Beijing 100871, China; 1600013387@pku.edu.cn \\ 3 Department of Architecture, Shanghai University, Shanghai 200072, China \\ * Correspondence: xiaorong17@shu.edu.cn
}

check for updates

Citation: Dai, L.; Zhan, Z.; Shu, Y.; Rong, X. Land Use Change in the Cross-Boundary Regions of a Metropolitan Area: A Case Study of Tongzhou-Wuqing-Langfang. Land 2022, 11, 153. https://doi.org/ 10.3390/land11020153

Academic Editor: Hualou Long

Received: 25 December 2021

Accepted: 13 January 2022

Published: 19 January 2022

Publisher's Note: MDPI stays neutral with regard to jurisdictional claims in published maps and institutional affiliations.

Copyright: (c) 2022 by the authors. Licensee MDPI, Basel, Switzerland. This article is an open access article distributed under the terms and conditions of the Creative Commons Attribution (CC BY) license (https:// creativecommons.org/licenses/by/ $4.0 /)$.

\begin{abstract}
Since the 1980s, metropolitan areas have increased worldwide due to urbanization and regionalization. While the spatial integration of the labor and housing markets has benefitted the development of cities within metropolitan areas, they have also brought great challenges for land governance; this is particularly evident in cross-boundary regions due to the complex relations between the markets and the regulations and between governments at different levels. Extensive research has been conducted on the city-level analysis of socioeconomic integration, land use development, and urban governance within metropolitan areas; yet, it is insufficient for understanding the intricate interplay between the various forces in such regions. This study aims to reveal the dynamics of land use change from 1990-2020 and its driving forces in the recent decade in the Tongzhou-Wuqing-Langfang (TWL) region-a typical cross-boundary area between Beijing, Tianjin, and the Hebei Metropolitan Area-using Landsat imagery. We employed the land-use dynamic degree, kernel density analysis, principal component analysis, and multiple linear regression to explore the spatiotemporal patterns of land use change and its driving factors at the district/county level. The results show that the general land use changes from cultivated and forest land to urban and rural construction land across the region. The speed of the trend varies considerably over time between different areas as the land use policies and regulations of each local government change. The population growth and the tertiary and secondary industry growth are the main driving factors for the change in construction land across the whole TWL region, while the urbanization rate and fixed asset investment have different impacts across the cross-boundary region. The results suggest that expanding the integration of land use policies and regulations in the cross-boundary region is urgently required.
\end{abstract}

Keywords: land use change; metropolitan area; cross-boundary management; driving factors

\section{Introduction}

Land use change (LUC) results from the interaction between human activities and natural biophysical processes and reflects human-land relationship changes. The Anthropocene epoch has caused changes in global land use, from primitive landscapes to urban and cultivated landscapes [1,2]. LUC extensively affects the ecological environment, biodiversity conservation, agricultural economy, climate, and sustainable development [3-7]. LUC is part of the complex human-land system, and multiscale LUC analysis is of great significance for model building, change prediction, and land management [8-11]. Extensive studies on LUC have been conducted at the international, national, regional, and urban levels [12-15].

Due to rapid population growth, industrialization, and urbanization, the metropolitan areas have developed rapidly worldwide, leading to large-scale spatial transformation and drastic LUC $[16,17]$. The application of remote sensing image recognition technology 
and the establishment of evaluation indicators has enabled the quantitative analysis of the process, dynamics, and mode of spatial change within metropolitan areas [18-21]. Many studies have used regression analysis, geographically weighted regression, and other econometric methods to explore the driving factors behind LUC in metropolitan areas [22-24], as well as the relationship between LUC and the changing process of ecosystem services and urban heat islands [25-27]. Simultaneously, other studies have used cellular automata, artificial neural networks, random decision forests, and Markov chains to simulate and predict the complex process of LUC in metropolitan areas [28-30].

Within metropolitan areas, government cooperation between cities and the spatial integration of the labor and housing markets are conducive to land use management [31,32]. However, cases from different fields worldwide have shown that socioeconomic contradictions and imbalances inevitably and universally exist within metropolitan areas [33-39]. Internal imbalance results in competition and conflict in land policy and development and brings new land use management challenges to metropolitan areas [40]. This imbalance phenomenon is concentrated in three areas: urban and rural regions, core and peripheral regions, and cross-boundary regions. Regarding the urban and rural regions, rapidly increasing urbanized areas that have significant resource concentrations attempt to seize water, agricultural land, and ecological resources from rural areas, leading to intense land use conflict [41-44]. Regarding the core and peripheral regions, the core areas continue to agglomerate resources and facilities, which exacerbates socioeconomic inequality and reduces social mobility [45-49]. Alternatively, the relative decline of the core areas results in the division of competitive, autonomous local governments [50,51]. Regarding the cross-boundary regions, due to market regulations and the complex relationships between governments at various levels, cross-boundary cooperation is often quite difficult to achieve, especially in the context of land use management. Meanwhile, crossboundary cooperation and management in some regions may also promote segregation as well as socioeconomic inequality $[52,53]$. However, compared with the urban/rural and core/peripheral regions, the literature has not paid enough attention to the cross-boundary regions within metropolitan areas.

Differences in economic conditions and management policies between administrative bodies result in complex dynamics in cross-boundary regions, which brings challenges in planning and management [54]. The extant research on cross-boundary regions falls into two categories. The first category comprises cross-boundary planning and management practices, particularly in Western countries where such practices are more common [55,56]. For example, Europe has established cross-border cooperation organizations and a supraregional institution-the European Territorial Cooperation Group [57]. Meanwhile, in China, attention has been paid to the regions that cross provincial boundaries, such as the Beijing-Tianjin-Hebei Greater Beijing Region, the Guangdong-Hong Kong-Macao Greater Bay Area, and the Fujian-Taiwan boundary region [58,59]. The second category comprises the causes of variability in the development status, land use, and ecological landscapes within cross-boundary regions. Some cross-boundary regions have become hotspots for regional development because of the effect of factor flows and agglomeration, which have more complex driving factors [60]. The rapid development of these cross-boundary regions has also been accompanied by problems such as a sharp increase in house prices and inadequate cross-boundary transportation provision. A common difficulty includes coordinating the conflicting interests of local governments, real estate developers, and other parties in land allocation to realize the optimal use of land in the border regions of urban areas in various countries [61].

In summary, the literature has mainly focused on socioeconomic development at the national and sub-national scale and has paid little attention to land use and spatial changes at the regional and sub-regional scale. A large gap exists between the complex LUC and the underlying mechanisms in the cross-boundary regions of metropolitan areas in fasturbanizing countries and the existing research. Therefore, this study aims to fill this gap by focusing on the LUC and its driving mechanisms in the Tongzhou-Wuqing-Langfang 
(TWL) - a typical cross-boundary region of the Beijing-Tianjin-Hebei Metropolitan Region in the Greater Beijing Region. As a rapidly urbanizing metropolitan area, the unbalanced development of the Greater Beijing Region and the contradiction in its human-land relationships appear to be prominent in the TWL region. The land management in the TWL region faces difficulties which are similar to those of other cross-boundary regions in fasturbanizing metropolitan areas. First, the basic socioeconomic conditions vary between districts and counties, making it difficult for the local governments to implement land and planning policies in a coordinated manner. Second, as residents on both sides of the administrative boundary are mobile and may have access to each other's information, the implementation of policies that have regional differences involving public interests will encounter significant resistance. Therefore, the case study of TWL may shed new light on understanding the current situation and the challenges of land management for metropolitan areas in fast-urbanizing countries.

\section{Methods}

\subsection{Research Area}

The Beijing-Tianjin-Hebei urban agglomeration is the "capital circle" of China. It is the largest and most dynamic region in northern China and has an important strategic position. Local governments initiated regional cooperation in the 1980s, while in the early 2000s the National Development and Reform Commission (NDRC) promoted regional coordination and communication and created regional development plans. In 2014, the coordinated development of Beijing-Tianjin-Hebei was promoted as a national strategy. The central government established the Beijing-Tianjin-Hebei Coordinated Development Leading Group and promoted transportation integration, industrial transfer, and joint air prevention and control in several vital sectors. However, the region still faces great problems, such as weak ecological and environmental protection, unbalanced development of the urban system, and a widening gap between regional and urban development, particularly due to the emergence of the poverty and pollution belts around Beijing. According to the Outline of China's 14th Five-Year Plan and 2035 Vision Goals, China will accelerate the coordinated development of the Beijing-Tianjin-Hebei Metropolitan Region, build a highquality sub-center in Beijing, and promote the integrated development of Beijing, Tianjin, and Hebei. This collaborative spatial development and sustainable urbanization of the Greater Beijing Region will have reference significance for the sustainable development of urban agglomerations in both China and other developing countries.

The TWL region is located at the intersection of Beijing, Tianjin, and Hebei and is a pilot demonstration area for the coordinated development of Beijing, Tianjin, and Hebei, as well as for regional policies (Figure 1). As critical areas connecting the Greater Beijing Region, Beijing's Tongzhou District, Tianjin's Wuqing District, and Hebei's Langfang City are closely interconnected spatially. They are important core areas for the coordinated development of Beijing-Tianjin-Hebei and are known as the TWL Golden Triangle. With a total land area of $8895 \mathrm{~km}^{2}$, the TWL region is located at the lower end of the North China alluvial plain. It has a gentle terrain and a total population of 7.78 million. The expansion of urban construction land in recent years has resulted in the rapid development of the suburban and rural construction land areas and persistent LUC.

Although they share a geographical border, these three areas of the TWL region fall under different administrative jurisdictions. As districts of the centrally-administered municipalities, the Tongzhou and Wuqing District governments cannot independently formulate and implement land management policies and are subject to the unified deployment of the Beijing and Tianjin municipal governments. Moreover, due to the particularity of Beijing's status, land use in Wuqing District and Langfang City often give way to Beijing's planning needs. 


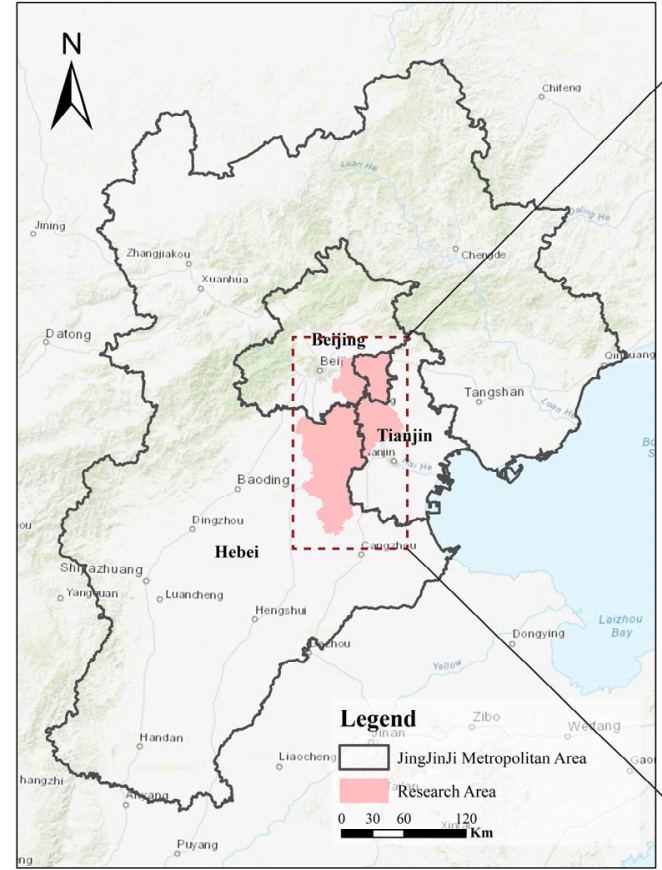

(a)

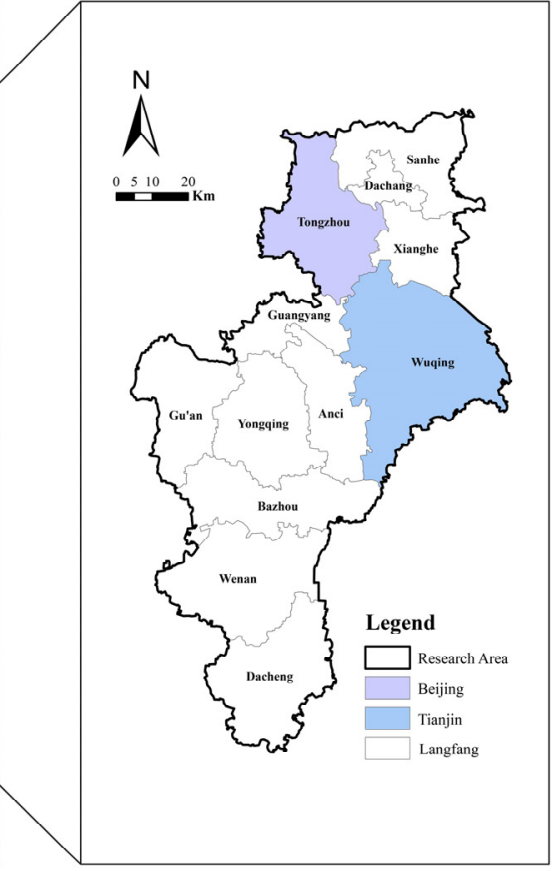

(b)

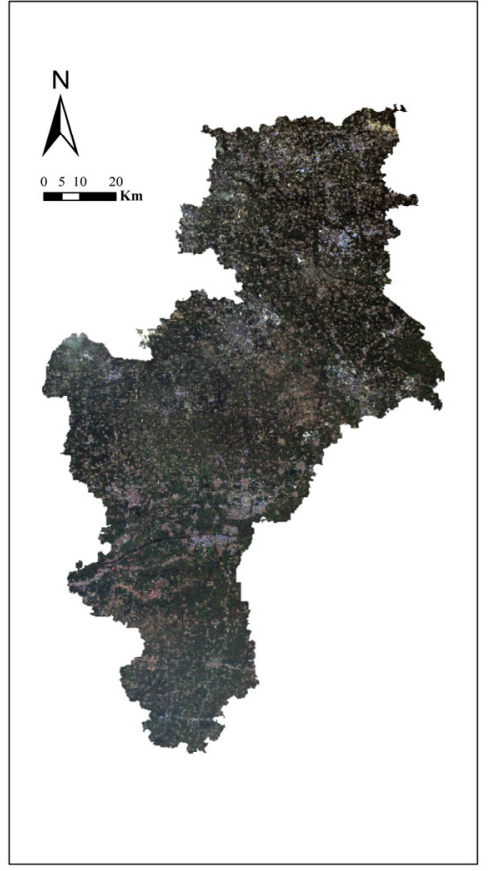

(c)

Figure 1. (a) Beijing-Tianjin-Hebei Metropolitan Region, (b) administrative map of TWL region, and (c) remote sensing image of TWL region (Source: authors based on United States Geological Survey).

The basic characteristics of Tongzhou, Wuqing, and Langfang (in 2019) are as follows. Tongzhou District is the eastern gate of Beijing. It borders Langfang's three northern counties (Sanhe City, Dachang Hui Autonomous County, and Xianghe County) in the east and Tianjin's Wuqing District and Langfang's Guangyang District in the south. Tongzhou District covers a total area of $904 \mathrm{~km}^{2}$ and has a permanent population of 1.675 million. The per capita GDP of Tongzhou District is CNY 63,236, and the percentage contributions of the primary, secondary, and tertiary industries to the total GDP are $1.2 \%, 39.9 \%$, and $59.0 \%$, respectively. Wuqing District is located on the northwest edge of Tianjin, at the center of Beijing and Tianjin, and covers an area of $1575 \mathrm{~km}^{2}$. Its permanent population totals 1.183 million, and its per capita GDP is CNY 74,932. The composition of the GDP by the three industries is $3.9 \%, 33.1 \%$, and $63.0 \%$. Langfang lies between Beijing and Tianjin and has 10 counties (cities and districts) under its jurisdiction that border Beijing and Tianjin. Langfang's three northern counties (Sanhe City, Dachang Hui Autonomous County, and Xianghe County) are enclaves, which are separated from the Langfang central urban area (Guangyang District and Anci District) and other counties and cities by Beijing and Tianjin. Langfang covers an area of $6415 \mathrm{~km}^{2}$ and has a permanent population of 4.921 million. Its per capita GDP is CNY 65,512, and the composition of the GDP by the three industries is $6.7 \%, 32.9 \%$, and $60.4 \%$.

\subsection{Data Sources}

The TWL region's land use data were obtained by interpreting the Landsat series 1 remote sensing image product (Collection 1, Level 1). The research on the land use in the TWL region used a time series that spanned from 1990-2020, and the interpretation and sampling interval was approximately 10 years. To minimize the seasonal impact on vegetation, the image acquisition period was controlled from June-September, and the cloud cover was less than $10 \%$. The data for each year were obtained from the latest available satellite remote sensing images that had the highest accuracy. This included Landsat 5 TM, Landsat 7 ETM+, and Landsat 8 OLI satellite remote sensing data that had a spatial resolution of $30 \mathrm{~m}$, Universal Transverse Mercator image projection, and a WGS84 datum level. We used the urban and rural construction land area data from the Beijing Land 
Use Survey (2008-2018) and the China Urban Construction Statistical Yearbook (2010-2020) to supplement the remote sensing interpretation results.

We obtained the socioeconomic data of Tongzhou, Wuqing, and Langfang (including the GDP, population, urbanization rate, and fixed asset investment) from the Beijing Statistical Yearbook (2010-2020), the Beijing Tongzhou District Statistical Yearbook (20102020), the Tianjin Statistical Yearbook (2010-2020), and the Hebei Economic Statistical Yearbook (2010-2020).

\subsection{Research Methods}

\subsubsection{Research Framework}

This research studies the LUC of the TWL region at the junction of Beijing-TianjinHebei at the district and county level and explores the mechanism of administrative barriers on the land use differences. We adopt a human-computer interaction method to process the remote sensing image. By direct interpretation of Landsat remote sensing images and a corresponding analysis, this study can avoid the inaccuracy of the production and processing of the existing remote sensing land use data. We carry out the quantitative analysis of LUC using, for example, the land-use dynamic degree and kernel density analysis, as well as qualitative analysis of the land management policies and regulations, to reveal the temporal and spatial LUC within TWL and in each district/county. Furthermore, we adopt principal component analysis and stepwise multiple linear regression to analyze the driving factors of construction land change. Based on the analysis results, we provide beneficial suggestions for planning and controlling the boundary regions in metropolitan areas for fast-urbanizing countries (Figure 2).

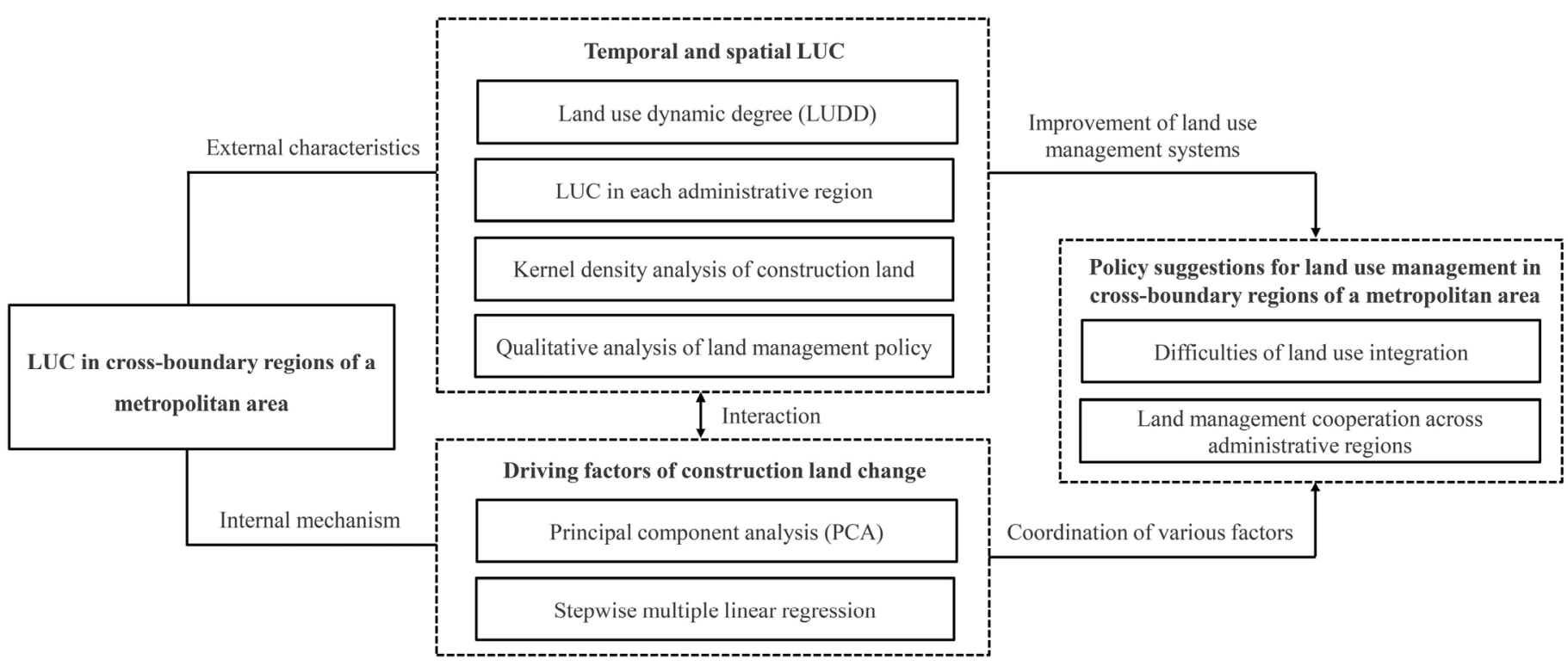

Figure 2. Research Framework (Source: authors).

\subsubsection{Pre-Treatment and Supervised Classification}

First, we pre-processed the original remote sensing image data and then conducted a registration, correction, and image fusion to establish a sample selection and classification system. By referring to the main classification categories of several past LUC studies [62,63], we divided the land types into five categories: construction land, unused land, cultivated land, forest land, and water bodies.

Supervised classification is also known as training area classification, in which the training area is established according to the defined land pixels; the discriminant function is trained by using the statistical information features of the training area; and then, the trained function is used to identify the land types of other pixels. Considering both the large area and the complex land use types in the TWL region, we made a comparative attempt 
to obtain more accurate classification and interpretation results using the Mahalanobis distance, the K-nearest neighbor method, maximum likelihood, and other classifiers. We adopted the maximum likelihood method classifier, which proved to have the best effect in classical supervised classification, to conduct a preliminary classification of the land use types using the TWL region's remote sensing images [64]. We used ENVI Classic software to correct the results via a visual interpretation, and the remaining unrecognized land categories were reclassified. We then compared the final interpretation results with the latest national land survey results in China. The accuracy rate was over $85 \%$; so, the results were considered reliable. The supervised classification allowed us to obtain the spatiotemporal evolution of LUC in the TWL region by comparing the spatial distribution land use maps in the four periods, while we could analyze the influence mechanism of the land management policies on LUC in the corresponding periods based on government documents and other materials.

\subsubsection{Land-Use Dynamic Degree}

The land-use dynamic degree (LUDD) is adopted to analyze the intensity of LUC within the TWL region as it directly reflects the intensity of a certain type of LUC within a certain time frame [65]. The formula is expressed as follows:

$$
\mathrm{Pi}=\left\{\sum_{j=1}^{n}\left(\frac{|\Delta S i \rightarrow j+\Delta S j \rightarrow i|}{S i}\right)\right\} \times \frac{1}{t} \times 100 \%
$$

where Pi represents the dynamic change degree of i-type land, $|\Delta S i \rightarrow j+\Delta S j \rightarrow i|$ represents the absolute sum of conversions between this land use type and other land use types, $S i$ represents the total area of this land use type, and $t$ is the study period. The larger the Pi value, the greater the conversion intensity between the i-type land and other land types.

The comprehensive LUDD reflects the overall change in the land use quantity. The formula is expressed as follows:

$$
\mathrm{P}=\left\{\sum_{i=1}^{n}\left(\frac{\left|S i-S i_{0}\right|}{S}\right)\right\} \times \frac{1}{t} \times 100 \%
$$

where $P$ represents the degree of dynamic change of all land use types in the study area, $\left|S i-S i_{0}\right|$ represents the difference between the final land area and the initial area for type $i, S$ is the total land area in the study area, and $t$ is the study period. The larger the value of $\mathrm{P}$, the more drastic the change in the whole land use type in the study area in a specific time frame.

\subsubsection{Kernel Density Analysis}

We adopt the kernel density analysis to analyze the urbanization process and the spatial expansion of built-up areas during the research period. As a non-parametric method, kernel density analysis can be easily implemented and can better reflect the distance attenuation effect in the spatial distribution of geographical phenomena [66]. This study employed the kernel density analysis module in ArcGIS 10.5 to conduct a weighted kernel density analysis of the construction land in the TWL region in the four phases, taking the construction land patch area as the weight.

\subsubsection{Analysis of Driving Factors}

Principal component analysis (PCA) is adopted to analyze the driving factors of the LUC in the TWL region. PCA refers to the dimensionality reduction in complex socioeconomic multi-variables. It calculates feature vectors to remove information overlap among similar factors and extract variable combinations that significantly contribute to the LUC of the construction land in the TWL region. 
The formula for the multiple stepwise linear regression model regarding the LUC of the construction land is as follows:

$$
\mathrm{Yi}=\beta_{0}+\beta_{1} x_{i 1}+\beta_{2} x_{i 2}+\beta_{3} x_{i 3}+\beta_{4} x_{i 4}+\cdots+\beta_{n} x_{i n}
$$

where Yi is the TWL region's total construction land area in year $i ; x_{i n}$ is the observed value of the nth explanatory variable, that is, the driving factor in year $i$; and $\beta_{i}$ is the parameter to be estimated. Stepwise regression analysis requires that each time a new independent variable is introduced, the old independent variable should be individually tested to eliminate the independent variables with an insignificant partial regression square sum. To establish the optimal multiple linear regression equation of the driving factors of the LUC of the construction land in each region of the TWL, we introduced and removed the variables until no new variables could be introduced and no variables could be deleted. Based on the conclusions from the previous empirical studies $[67,68]$, and by considering the availability of statistical data, we selected eight indicators from the Tongzhou, Wuqing, and Langfang statistical yearbooks (2010-2020) as the driving factors of the construction LUC: the output value of secondary industry (X1); the output value of tertiary industry (X2); the investment in fixed assets (X3); the total retail sales of social consumer goods (X4); the population of permanent residents (X5); the urbanization rate (X6); the per capita disposable income of the residents (X7); and the local general financial budget expenditure (X8).

\section{Results and Analysis}

\subsection{Spatiotemporal Evolution of LUC}

The results of the remote sensing image data from 1990, 2000, 2010, and 2020 show that the land use in the TWL region has, over the past 30 years, undergone significant changes, which are mainly reflected in the transformation of arable land and unused land into construction land, as well as the large-scale expansion of the urban built-up areas (Figure 3). Overall, the construction land of each administrative unit experienced three phases, i.e., "disorderly expansion, rapid expansion, and incremental slowdown", but the expansion speed varies between them. Eventually, a construction corridor was formed with density peaks scattered in the TWL region (Figure 4). From the LUDD perspective, the LUC rate in the TWL region increased slowly from $1.26 \%$ in $1990-2000$ to $2.29 \%$ in $2000-2010$ and then decreased to $0.78 \%$ in 2010-2020 (Table 1). The LUC rates of construction land, arable land, and water bodies are relatively stable, and the LUDD of forest land increased rapidly in 2000-2010. The LUDD of unused land fluctuated significantly owing to the small area size and the influence of climate.

Table 1. Land-use dynamic degree in the TWL region (1990-2020).

\begin{tabular}{ccccc}
\hline \multirow{2}{*}{ Land-Use Dynamic Degree } & Land Use Type & \multicolumn{2}{c}{ Period } \\
\cline { 3 - 5 } & & $\mathbf{1 9 9 0 - 2 0 0 0}$ & $\mathbf{2 0 0 0 - 2 0 1 0}$ & $\mathbf{2 0 1 0 - 2 0 2 0}$ \\
\hline Comprehensive dynamic degree & Total & $0.99 \%$ & $2.54 \%$ & $0.78 \%$ \\
\hline & Construction land & $3.91 \%$ & $4.97 \%$ & $1.91 \%$ \\
Single dynamic degree & Unused land & $1.59 \%$ & $9.60 \%$ & $142.85 \%$ \\
& Arable land & $0.65 \%$ & $1.64 \%$ & $0.26 \%$ \\
& Forest land & $8.09 \%$ & $25.44 \%$ & $6.84 \%$ \\
& Water bodies & $11.52 \%$ & $12.98 \%$ & $6.08 \%$ \\
\hline
\end{tabular}



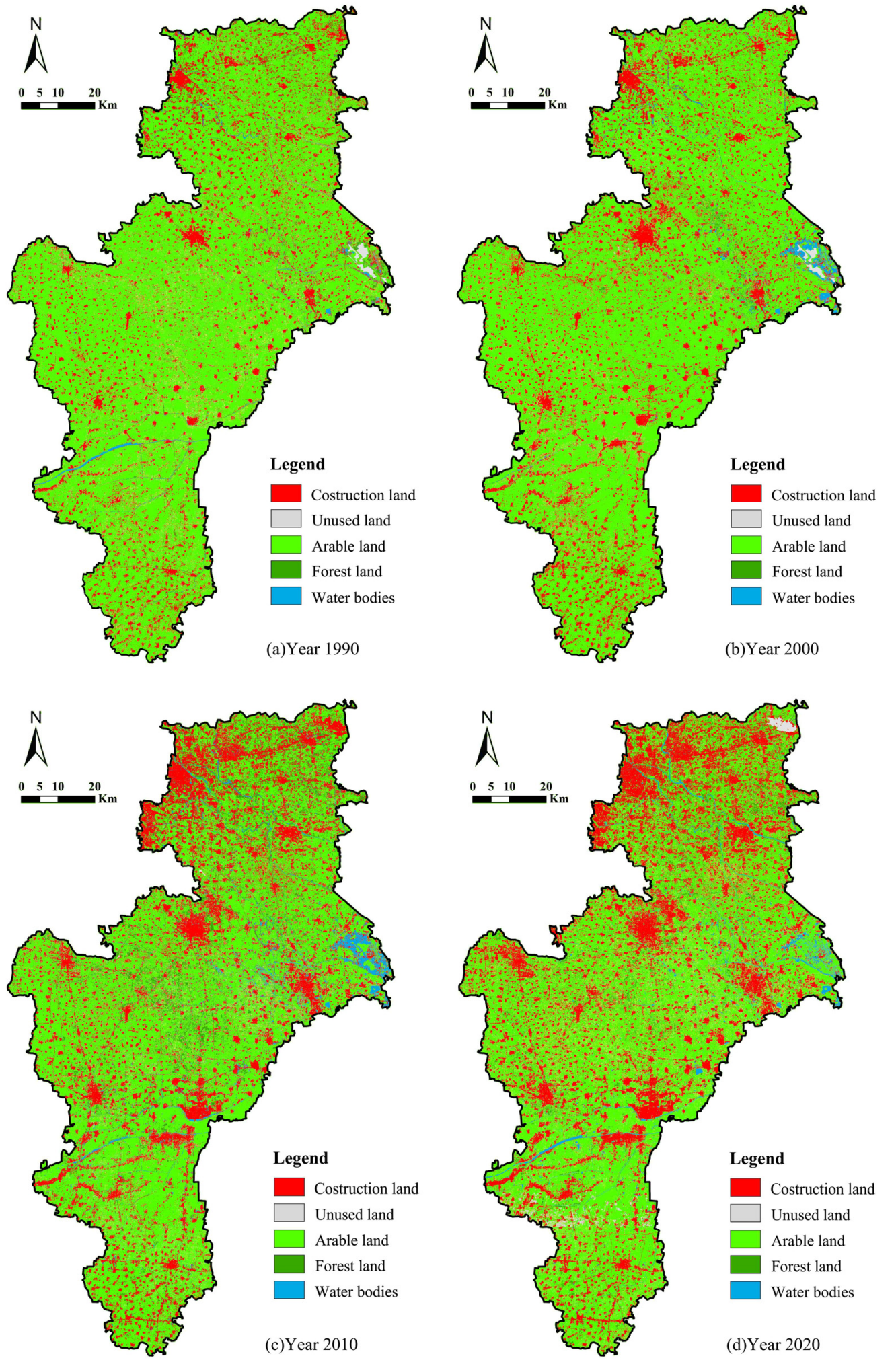

Figure 3. Spatial distribution of land use in the TWL region in (a) 1990, (b) 2000, (c) 2010, and (d) 2020 (Source: authors). 


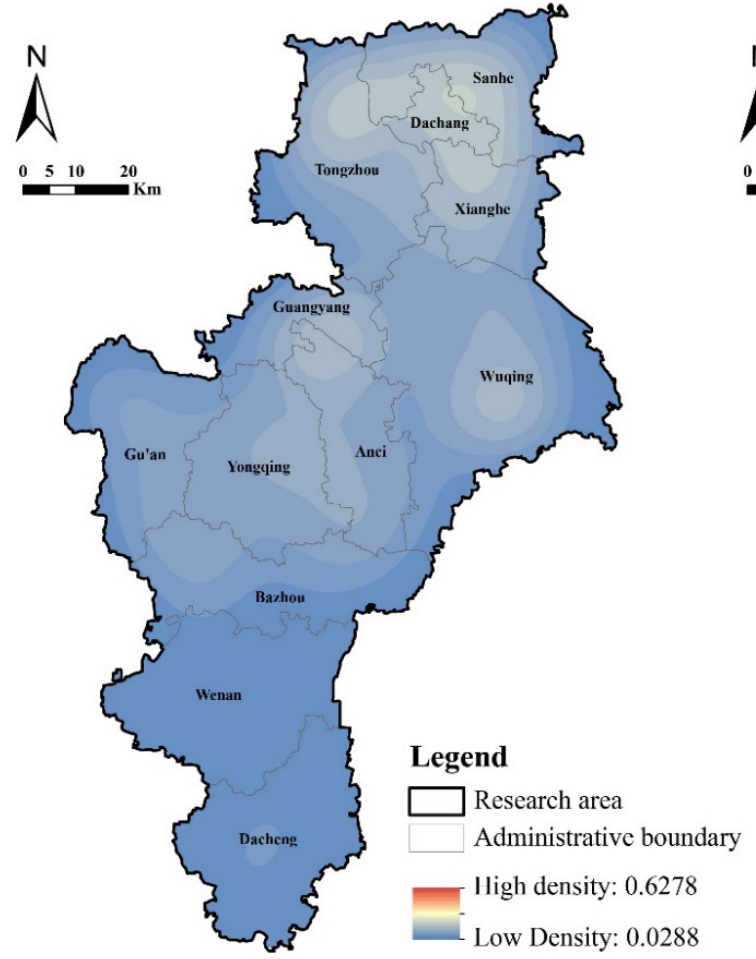

(a) Year 1990

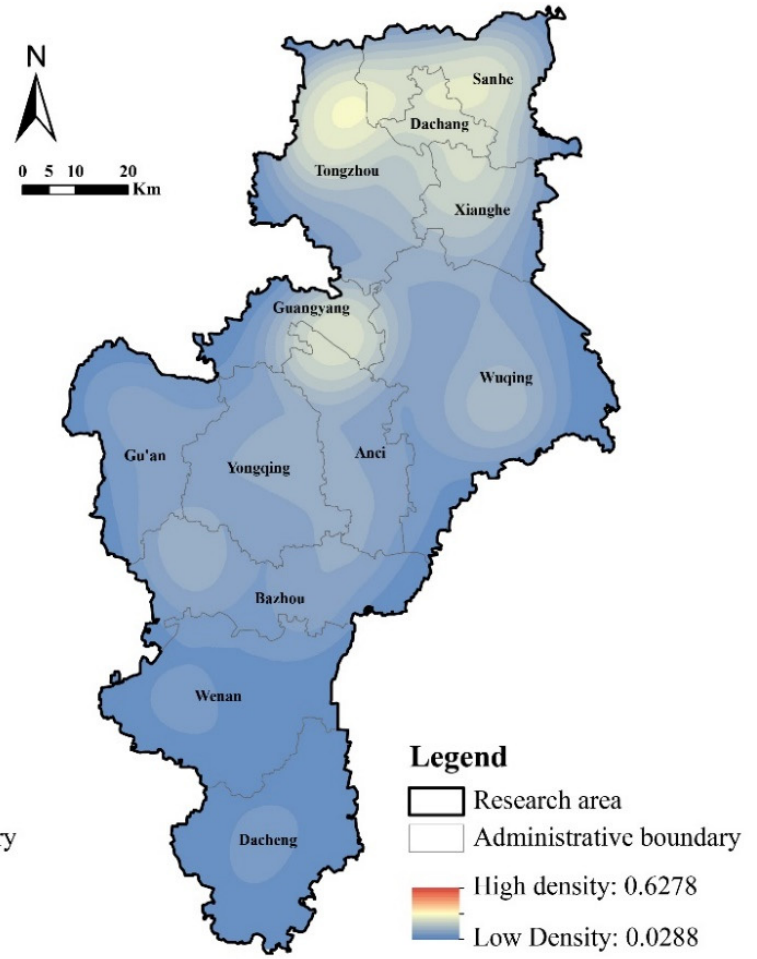

(b) Year 2000

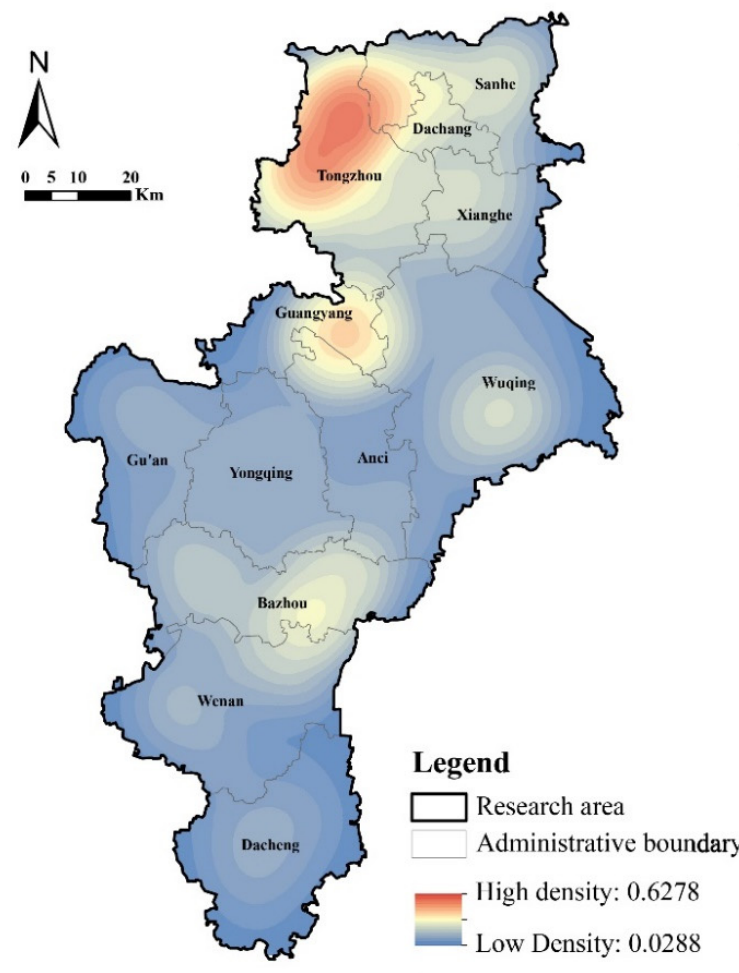

(c) Year 2010

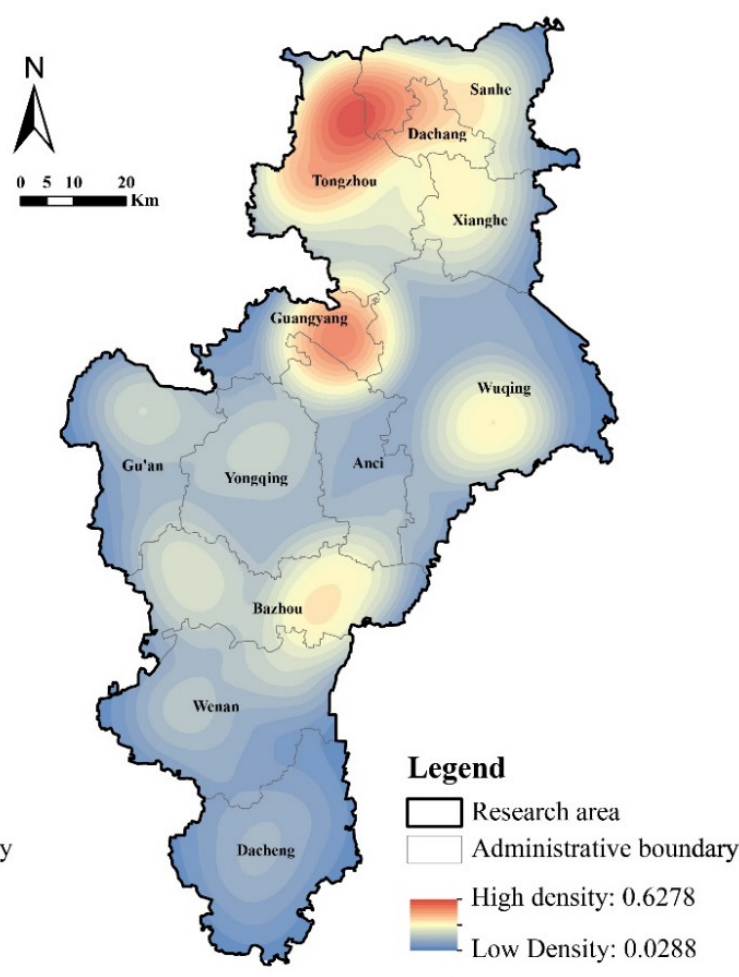

(d) Year 2020

Figure 4. Kernel density analysis of construction land in the TWL region in (a) 1990, (b) 2000, (c) 2010, and (d) 2020 (Source: authors). 
From the land use structure perspective, arable land continues to decline from $83.2 \%$ in 1990 to $67.3 \%$ in 2020 but remains the largest land use type in the TWL region. Construction land had a $121.6 \%$ rapid increase from 1990-2020, from $11.4 \%$ in 1990 to $25.2 \%$ in 2020 . Although the change rate is larger, the forest land and the water bodies show a lower proportion. Unused land remains the lowest among all the land use types and varies from $0.001-0.3 \%$ (Table 2 ).

Table 2. Land use structure of the TWL region from 1990-2020 $\left(\mathrm{km}^{2}\right)$ and percentage change in each decade $(\%)$.

\begin{tabular}{|c|c|c|c|c|c|c|c|}
\hline Region & Time & $\begin{array}{c}\text { Construction } \\
\text { Land }\end{array}$ & $\begin{array}{l}\text { Unused } \\
\text { Land }\end{array}$ & Arable Land & Forest Land & $\begin{array}{l}\text { Water } \\
\text { Bodies }\end{array}$ & Total \\
\hline \multirow{6}{*}{ TWL region } & 1990 & 1011.94 & 22.53 & 7399.30 & 366.34 & 94.72 & 8894.82 \\
\hline & 2000 & $\begin{array}{l}1367.05 \\
(35.1 \%)\end{array}$ & $\begin{array}{c}19.85 \\
(-11.9 \%)\end{array}$ & $\begin{array}{l}7132.63 \\
(-3.6 \%)\end{array}$ & $\begin{array}{c}195.72 \\
(-46.6 \%)\end{array}$ & $\begin{array}{c}179.57 \\
(89.6 \%)\end{array}$ & 8894.82 \\
\hline & \multirow[b]{2}{*}{2010} & 1914.84 & 1.41 & 6023.56 & 602.57 & 352.45 & \multirow[b]{2}{*}{8894.82} \\
\hline & & $(40.1 \%)$ & $(-92.9 \%)$ & $(-15.5 \%)$ & $(207.9 \%)$ & $(96.3 \%)$ & \\
\hline & \multirow{2}{*}{2020} & 2242.62 & 20.08 & 5983.72 & 449.88 & 198.52 & \multirow{2}{*}{8894.82} \\
\hline & & $(17.1 \%)$ & $(1328.5 \%)$ & $(-0.7 \%)$ & $(-25.3 \%)$ & $(-43.7 \%)$ & \\
\hline \multirow{7}{*}{$\begin{array}{l}\text { Tongzhou } \\
\text { District of } \\
\text { Beijing }\end{array}$} & 1990 & 136.50 & 0.04 & 705.37 & 44.23 & 18.30 & 904.43 \\
\hline & & 168.75 & 0.04 & 690.93 & 10.34 & 34.37 & \multirow{2}{*}{904.43} \\
\hline & 2000 & $(23.6 \%)$ & $(0.0 \%)$ & $(-2.0 \%)$ & $(-76.6 \%)$ & $(87.8 \%)$ & \\
\hline & \multirow{2}{*}{2010} & 260.49 & 0.94 & 529.64 & 72.32 & 41.05 & \multirow[b]{2}{*}{904.43} \\
\hline & & $(54.4 \%)$ & $(2242.3 \%)$ & $(-23.3 \%)$ & $(599.6 \%)$ & $(19.4 \%)$ & \\
\hline & \multirow[b]{2}{*}{2020} & 301.57 & 0.03 & 530.60 & 48.43 & 23.80 & \multirow[b]{2}{*}{904.43} \\
\hline & & $(15.8 \%)$ & $(-96.8 \%)$ & $(0.2 \%)$ & $(-33.0 \%)$ & $(-42.0 \%)$ & \\
\hline \multirow{6}{*}{$\begin{array}{l}\text { Wuqing } \\
\text { District of } \\
\text { Tianjin }\end{array}$} & 1990 & 178.25 & 22.46 & 1232.33 & 118.17 & 24.23 & 1575.43 \\
\hline & & 242.43 & 19.79 & 1127.04 & 100.83 & 85.34 & \multirow{2}{*}{1575.43} \\
\hline & 2000 & $(36.0 \%)$ & $(-11.9 \%)$ & $(-8.5 \%)$ & $(-14.7 \%)$ & $(252.2 \%)$ & \\
\hline & \multirow{2}{*}{2010} & 325.44 & 0.02 & 1015.07 & 110.30 & 124.60 & \multirow{2}{*}{1575.43} \\
\hline & & $(34.2 \%)$ & $(-99.9 \%)$ & $(-9.9 \%)$ & $(9.4 \%)$ & $(46.0 \%)$ & \\
\hline & 2020 & $\begin{array}{c}360.05 \\
(10.6 \%)\end{array}$ & $\begin{array}{c}0.03 \\
(50.0 \%)\end{array}$ & $\begin{array}{c}1042.23 \\
(2.7 \%)\end{array}$ & $\begin{array}{c}106.47 \\
(-3.5 \%)\end{array}$ & $\begin{array}{c}66.65 \\
(-46.5 \%)\end{array}$ & 1575.43 \\
\hline \multirow{7}{*}{$\begin{array}{l}\text { Langfang } \\
\text { City (Except } \\
\text { the three } \\
\text { northern } \\
\text { counties) }\end{array}$} & 1990 & 530.84 & 0.01 & 4460.09 & 129.15 & 36.79 & 5156.88 \\
\hline & & 770.87 & 0.01 & 4317.54 & 39.15 & 29.32 & \multirow{2}{*}{5156.88} \\
\hline & 2000 & $(45.2 \%)$ & $(0.0 \%)$ & $(-3.2 \%)$ & $(-69.7 \%)$ & $(-20.3 \%)$ & \\
\hline & \multirow{2}{*}{2010} & 981.04 & 0.42 & 3749.61 & 284.35 & 141.46 & \multirow{2}{*}{5156.88} \\
\hline & & $(27.3 \%)$ & $(4085.0 \%)$ & $(-13.2 \%)$ & $(626.3 \%)$ & $(382.5 \%)$ & \\
\hline & \multirow{2}{*}{2020} & 1179.74 & 0.05 & 3689.74 & 206.42 & 80.94 & \multirow{2}{*}{5156.88} \\
\hline & & $(20.3 \%)$ & $(-88.1 \%)$ & $(-1.6 \%)$ & $(-27.4 \%)$ & $(-42.8 \%)$ & \\
\hline \multirow{7}{*}{$\begin{array}{l}\text { Three } \\
\text { northern } \\
\text { counties of } \\
\text { Langfang }\end{array}$} & 1990 & 166.35 & 0.02 & 1001.51 & 74.79 & 15.40 & 1258.08 \\
\hline & 2000 & 185.00 & 0.01 & 997.12 & 45.39 & 30.55 & \multirow{2}{*}{1258.08} \\
\hline & 2000 & $(11.2 \%)$ & $(-50.0 \%)$ & $(-0.4 \%)$ & $(-39.3 \%)$ & $(98.4 \%)$ & \\
\hline & 2010 & 347.86 & 0.03 & 729.24 & 135.60 & 45.35 & \multirow{2}{*}{1258.08} \\
\hline & & $(88.0 \%)$ & $(200.0 \%)$ & $(-26.9 \%)$ & $(198.7 \%)$ & $(48.4 \%)$ & \\
\hline & \multirow{2}{*}{2020} & 401.27 & 19.97 & 721.15 & 88.56 & 27.13 & 1258.08 \\
\hline & & $(15.4 \%)$ & $(66,454.9 \%)$ & $(-1.1 \%)$ & $(-34.7 \%)$ & $(-40.2 \%)$ & \\
\hline
\end{tabular}

3.1.1. 1990-2000: Low-Level and Disorderly Expansion of Construction Land

From 1990-2000, the TWL region's LUC shows that arable land, forest land, and unused land were transformed into construction land. Construction land increased by $355.1 \mathrm{~km}^{2}$ (35.1\%) over 10 years, of which $99.2 \%$ is from agricultural land. In total, $437.3 \mathrm{~km}^{2}$ of agricultural land, including arable land and forest land, was reduced. The water bodies increased by $89.6 \%$, mainly because of the significant expansion of the Chaobai River in Tongzhou and the Dahuangbao Wetland in Wuqing. These changes reflect the overall urban LUC in China. In the 1990s, due to the sharp contradiction between "more people, less land" and the lack of unified land use planning, agricultural land was randomly expropriated for 
urban construction. This seriously interfered with the overall planning of the towns and villages and resulted in macro, out-of-control land resource utilization [69].

From 1990-2000, the total construction land growth in Langfang was higher than the growth in Tongzhou and Wuqing. Langfang City (except for the three northern counties) had the fastest construction land growth rate $(45.2 \%)$ over 10 years, and the newly-added land has been expanded to the surrounding areas from the original central towns of each district and county. Areas with relatively dense construction land occurred in Wenan, Dacheng, and Bazhou, where the initial scale of construction land had been relatively small. Simultaneously, forest land experienced the greatest decline, at $90.0 \mathrm{~km}^{2}(69.7 \%)$. Meanwhile, the construction land only expanded by $11.2 \%$ in the three northern counties. This was mainly due to the rapid development of urban construction and the economy, which caused the construction land for urban development zones and real estate projects around the Langfang urban area to rapidly increase and occupy a large amount of cultivated land and other agricultural land. Langfang's first edition of the land use master plan was formulated in 1993. As an early exploration of China's land use management policy, it proposed that land use should be included in the government's annual management plan and that construction land should be arranged as a whole to better deal with the contradiction between agricultural land and construction land. However, the allocation principle of the construction land index in this plan was mainly to meet the needs of the population development. Therefore, more new construction land was allocated to Anci District (central urban area of Langfang) and Bazhou City, whose population was predicted to increase. As such, Tongzhou District and Wuqing District added $32.3 \mathrm{~km}^{2}$ and $64.2 \mathrm{~km}^{2}$ of new construction land, respectively. During this period, the urban planning of Beijing and Tianjin positioned the two counties as the marginal suburban area of the metropolitan circle. Therefore, they were assigned the function of being primary agricultural production suppliers and were not allocated many construction land indicators. As a result, their overall increment is lower than that of Langfang. However, in practice, it was a trend for the local governments to attract investment in the developing industries during this period. Every year, the local governments attempted to increase the land supply for the construction of an industrial park. Therefore, the growth rate of the construction land in these two areas reached $23.6 \%$ and $36.0 \%$, respectively, during this period.

\subsubsection{0-2010: Rapid Expansion under the Influence of Multiple Policies}

From 2000-2010, the overall pattern of land use in the TWL region changed considerably due to the conversion of a large amount of unused land and cultivated land into construction land. Construction land increased by $547.8 \mathrm{~km}^{2}$ (a $40.1 \%$ growth rate); unused land decreased by $18.4 \mathrm{~km}^{2}$; and agricultural land decreased significantly, with considerable changes to its internal structure. Arable land decreased by $1109.1 \mathrm{~km}^{2}$, and forest land increased by $406.9 \mathrm{~km}^{2}$. This indicates that after the tax-sharing reform and the turn towards economic growth-oriented assessment, local governments enlarged the macroeconomic growth function of land by choosing to develop a service industry (e.g., real estate), which greatly contributed to local fiscal revenue [70,71]. Land use plans that were formulated in various places all proposed to effectively protect agricultural land, designate primary farmland protection zones, and strengthen the construction of crucial forestry projects. However, in the construction projects' management procedures, the land administration authorities were not able to publish their opinions at the very beginning; thus, it was challenging to fully implement their ideas [72]. Subsequently, a large amount of arable land became occupied. During this period, the construction of the Greater Beijing Region was affected by the preparations for the Beijing Olympic Games. To create a suitable environment for the Games, the central government required the local governments of all districts and counties around Beijing to regard afforestation as a critical project and then assessed the local government leaders. As a result, the local governments conducted extensive afforestation, and forest land was restored to varying degrees in all sub-districts of the TWL region: $406.9 \mathrm{~km}^{2}$ was added overall. 
During this period, the construction land in Tongzhou District increased by $54.4 \%$. This is mainly because Beijing's urban construction shifted downtown to the outer suburbs. Tongzhou was identified as a satellite city for critical development because of its proximity to the downtown area and better development conditions. The rapid expansion of urban construction land also took place in the three northern counties, with $162.9 \mathrm{~km}^{2}$ of new construction land added (a 88.0\% increase). Meanwhile, arable land decreased by $267.9 \mathrm{~km}^{2}(26.9 \%)$. This is because Langfang proposed to build North Langfang New Town by taking advantage of its location around Beijing, and the three northern counties adjacent to Tongzhou obtained more construction land indicators. Simultaneously, Beijing's soaring property prices and draconian hukou restrictions made the three easily accessible northern counties a residential option for nearly 300,000 lower-income migrants in Beijing. Faced with this massive housing market demand, the decision-making departments of the three northern counties' local governments chose to ignore the construction of infrastructure and industrial support and instead magnified the value of the real estate market. The construction land in the three northern counties and Tongzhou shows a preliminary integration trend along the traffic arteries extending across the district, as demonstrated by the highest density peak near the administrative boundary of Tongzhou, Sanhe, and Dachang. New construction land increased by $34.2 \%$ in Wuqing, mainly in the industrial parks near the central city, and extended northwest toward the Langfang and Tongzhou Districts. During this period, Wuqing arranged for industrial land to be constructed along the newly built Beijing-Tianjin-Tang expressway to strengthen its industrial connection with Beijing and Langfang and drive the development of high-tech industries. To increase investment attraction, the Wuqing District government subsidized industrial enterprises in the disguised form of free land transfer and low prices, which resulted in low land use efficiency and insufficient economic benefits. In general, the connection between Tongzhou, Wuqing, and Langfang was gradually strengthened through market incentives and policies. However, the coordinated development of the TWL region did not receive enough attention from the three regions' governments, and the decision-making perspective was limited to short-term economic benefits within their respective administrative regions.

\subsubsection{0-2020: Strict Control of the Scale of Incremental Construction Land}

From 2010-2020, the TWL region's overall LUC shows that a small amount of cultivated land and forest land was transformed into construction land and unused land. Compared with the previous period, the expansion rate of the construction land in the whole region decreased significantly, and only increased by $17.1 \%$. Agricultural land decreased by $192.5 \mathrm{~km}^{2}$, unused land increased by $18.7 \mathrm{~km}^{2}$, and the water bodies decreased by $43.7 \%$. Due to various problems, such as the demand for construction land exceeding expectations and the poor implementation of the protection of cultivated land, the land use planning in all regions emphasized critically controlling construction land, vigorously promoting economic and intensive land use and determining an obligatory target and anticipatory target system. Furthermore, the responsibility system of cultivated land protection and economical and intensive land use of governments at all levels was established to implement the strictest cultivated land protection system. The assessment system of the local officials' cultivated land protection responsibility was improved by taking the actual quantity of cultivated land, the protected area of basic farmland, and the balance between the occupation and supplement of arable land as essential contents. With the establishment of the central government's Beijing-Tianjin-Hebei Coordinated Development Leading Group in 2014, the coordinated development of the TWL region, gradually became the focus of the Beijing, Tianjin, and Hebei provincial governments.

During this period, the growth rate of construction land slowed in most of the regions. Compared with the other regions, Langfang had the fastest growth rate of construction land, at $20.3 \%$. This is mainly because Langfang consciously strengthened its industry cooperation with Beijing and Tianjin, proposed the construction of a modern manufacturing industry belt around Beijing along the Mizhuo Highway, and suggested the construction 
of characteristic industries around Tianjin along the Langbo Highway. The expansion rates of construction land in Tongzhou District and Langfang's three northern counties decreased significantly and showed a $15.8 \%$ and $15.4 \%$ increase, respectively $\left(94.5 \mathrm{~km}^{2}\right.$ in total). It is noteworthy that the density peak of construction land has moved northwards, i.e., closer to Langfang's three northern counties. As a result, the spatial integration of Tongzhou, Dachang and Sanhe has increased. Tongzhou District was established as the sub-administrative center of Beijing, and the construction land supply of Tongzhou New Town was firmly guaranteed by the Beijing government; it obtained $46.7 \mathrm{~km}^{2}$ in this period, which was higher than all the other districts and counties in Beijing. However, it was not significant when compared with the previous increment from 2000-2010. In order to solve problems, such as the disorderly spread of construction land and the unorganized real estate along the administrative boundary between Tongzhou and the three northern counties of Langfang, the NDRC, the Ministry of Land and Resources, and seven other departments jointly formulated the "Guiding Opinions on Strengthening the Planning and Construction Management of the Beijing-Hebei Boundary Area" in 2016. According to this document, the scale of incremental construction land should be strictly controlled under the principle of unified planning and control, and the large-scale development of real estate and the hoarding and speculation of land in the border areas should be strictly prohibited in order to control the rapid growth of construction land around the capital to a certain extent. Because Wuqing District undertook the task of protecting the largest amount of agricultural land among all the districts and counties of Tianjin, the construction land increased the least, at only $10.6 \%$. Unlike in the previous stage (which focused on industrial development) Wuqing, following Langfang's three northern counties, also vigorously developed its residential land and tertiary industries to serve the commuter population from Beijing and Tianjin, after opening the Beijing-Tianjin intercity railway in 2008.

\subsection{Driving Factors of Construction Land}

\subsubsection{PCA of Driving Forces}

The 2010-2020 period was the period in which the Greater Beijing Region began to implement coordinated development. The analysis of the driving factors in this period has important reference significance for the formulation of land-use related policies in the future. As the socio-economic data of 2020 has not been fully published, we focus on analysis of the development of construction land from 2010-2019 instead.

Table 3 shows that the Pearson's correlation coefficients of the X1, X2, X3, X4, X5, and $X 8$ variables are all greater than 0.7 , indicating a strong positive correlation between the regional output value of the secondary and tertiary industries, the retail sales of consumer goods, the resident population, and the local budgetary expenditure. This also reflects the close relationship between the population, economic development, the residents' living standards, and government input. We performed correlation analysis using the KMO and Bartlett sphericity tests. The KMO value is 0.761 , and the $p$ value is below 0.05 , indicating that the original variable is suitable for factor analysis and the PCA can be conducted. The principal components were extracted according to the principle of the cumulative contribution rate $(>70 \%$ and eigenvalue $>1)$. The results show that the cumulative contribution ratio of the first two principal component variances is $90.397 \%$. 
Table 3. Correlation coefficient matrix of the driving factors (2010-2019).

\begin{tabular}{cccccccc}
\hline Factor & $\mathbf{X 1}$ & $\mathbf{X 2}$ & $\mathbf{X 3}$ & $\mathbf{X} 4$ & $\mathbf{X 5}$ & $\mathbf{X 6}$ & $\mathbf{X 7}$ \\
\hline X1 & 1.000 & & & & & & \\
X2 & $0.860^{* *}$ & 1.000 & & & & \\
X3 & $0.817^{* *}$ & $0.948^{* *}$ & 1.000 & & & \\
X4 & $0.831^{* *}$ & $0.967^{* *}$ & $0.936^{* *}$ & 1.000 & & & \\
X5 & $0.962^{* *}$ & $0.814^{* *}$ & $0.726^{* *}$ & $0.789^{* *}$ & 1.000 & & \\
X6 & 0.046 & 0.222 & 0.088 & $0.327^{*}$ & 0.097 & 1.000 & 1.000 \\
X7 & 0.100 & 0.235 & 0.260 & $0.379^{*}$ & 0.173 & $0.648^{* *}$ & $0.466^{* *}$ \\
X8 & $0.793^{* *}$ & $0.923^{* *}$ & $0.878^{* *}$ & $0.957^{* *}$ & $0.732^{* *}$ & $0.431^{* *}$ & 1.000 \\
\hline
\end{tabular}

* indicates that the correlation is significant at the 0.05 level, ${ }^{* *}$ indicates that the correlation is significant at the 0.01 level.

In the first principal component, $\mathrm{X} 1, \mathrm{X} 2, \mathrm{X} 3, \mathrm{X} 4, \mathrm{X} 5$, and $\mathrm{X} 8$ have a high load, which shows a concentrated reflection of the change in population and the total production investment in economic activities in the TWL region. In the second principal component, X6 and X7 have high loads, which shows a concentrated reflection of the urban and rural structure and the living income level of residents in the TWL region (Table 4). The sequence structure of two principal components shows that among the many socioeconomic driving factors, the regional population and the economic aggregate (Composition 1) determine the direction of construction LUC overall, and the urban-rural population structure and income level changes (Composition 2) may also have a certain effect. The socioeconomic driving factors of construction LUC in the TWL region show the interactive characteristics of having "population economic growth and changes in urban-rural structure and income level".

Table 4. Component matrix (after rotation).

\begin{tabular}{ccccc}
\hline Code & DRIVING Factor & Unit & Composition 1 & Composition 2 \\
\hline X1 & Output value of secondary industry & Billion RMB & 0.964 & 0.134 \\
X2 & Output value of tertiary Industry & Billion RMB & 0.958 & 0.195 \\
X3 & Investment in fixed assets & Billion RMB & 0.924 & 0.159 \\
X4 & Total retail sales of consumer goods & Billion RMB & 0.932 & 0.330 \\
X5 & Population of permanent resident & Thousand persons & 0.926 & 0.162 \\
X6 & Urbanization rate & \% & 0.096 & 0.846 \\
X7 & Per capita disposable income of residents & RMB & 0.049 & 0.946 \\
X8 & General financial budget expenditure & Billion RMB & 0.881 & 0.437 \\
\hline
\end{tabular}

We obtained the expressions of the first and second principal components according to the factor score coefficient and the standardized value of the original variable. By taking the proportion of the variance percentage as each principal component's characteristic value and the total percentage of cumulative variance of the first two principal components as the weight, we could calculate the principal component comprehensive score, that is, the score of the socioeconomic comprehensive driving force of LUC. According to Formula (4), the comprehensive driving factors of construction LUC in the TWL region mainly depend on regional population and economic aggregate changes:

$$
F=\mu_{1} F_{1}+\mu_{2} F_{2}=\frac{65.167}{90.397} F_{1}+\frac{25.230}{90.397} F_{2}
$$

The comprehensive score of the driving force of construction LUC in the TWL region presents a balanced and stable trend of continuous increase from 2010-2019: it rises from -1.320 in 2010 to 1.298 in 2019, has the largest increase from 2014-2015, and then flattens out (Figure 5). This indicates the increasingly strong influence of the socioeconomic driving forces on construction LUC in the TWL region. 


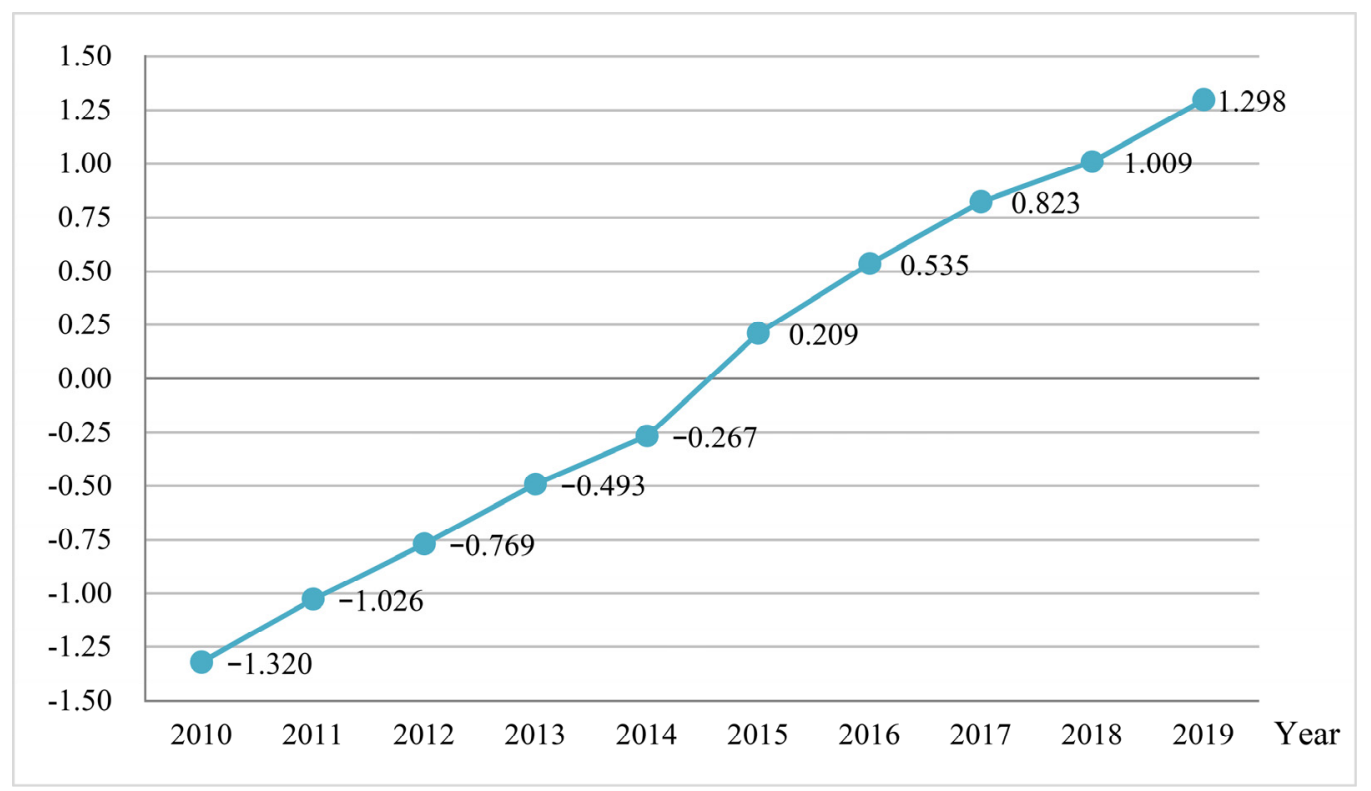

Figure 5. Comprehensive score of the driving forces of construction land in the TWL region (2010-2019).

\subsubsection{Regression Analysis of Driving Factors}

To further explore the driving factors of the regional construction land, we set the construction land area as the dependent variable and set the secondary industry's output value $(X 1)$, the tertiary industry's output value (X2), the permanent population (X5), the urbanization rate $(\mathrm{X} 6)$, and the per capita disposable income $(X 7)$ as the explained variable. These explained variables are selected because they are significant in the $t$ test in the preliminary regression. The OLS regression results are shown in Table 5 . The $\mathrm{R}^{2}$ of the entire model is 0.999 (Prob $>\mathrm{F}=0.000$ ).

Table 5. Estimation results of the driving factors in the TWL region using stepwise regression (2010-2019).

\begin{tabular}{cccccc}
\hline Code & Variable & Coefficient & $\begin{array}{c}\text { Standardized } \\
\text { Coefficient Beta }\end{array}$ & $t$ & Significant \\
& (constant) & 265.319 & & 11.581 & $0.000^{* *}$ \\
X1 & Output value of secondary industry & 1.283 & 0.087 & 2.996 & $0.006^{* *}$ \\
X2 & Output value of tertiary Industry & 1.409 & 0.124 & 7.546 & $0.000^{* *}$ \\
X5 & Population of permanent residents & 0.277 & 0.801 & 27.496 & $0.000^{* *}$ \\
X6 & Urbanization rate & -436.674 & -0.075 & -7.420 & $0.000^{* *}$ \\
X7 & Per capita disposable income of residents & -0.005 & -0.073 & -5.944 & $0.000^{* *}$ \\
\hline
\end{tabular}

${ }^{* *}$ indicates that the correlation is significant at the 0.01 level.

According to the model optimization results in Table 5, we can establish the driving force model of construction land expansion in the TWL region from 2010-2019. The formula is as follows:

$$
\begin{aligned}
& \text { Construction LandArea of TWL } \\
& \qquad \begin{aligned}
= & 1.283 \times \text { Secondary }+1.409 \times \text { Tertiary }+0.277 \times \text { Pop } \\
- & 436.674 \times \text { Urban }-0.005 \times \text { Income }+265.319
\end{aligned}
\end{aligned}
$$

The results show that the permanent population has the strongest influence on the growth of construction land in the TWL region. The output value of the tertiary and secondary industries also has a certain influence, and the influence of the tertiary output value is higher than that of the secondary output value. The increase in the permanent 
resident population plays a leading role in driving the growth of the construction land area, which reflects the policy logic of determining land by people in the TWL region. The standardized coefficient of the urbanization rate and the per capita disposable income of the residents is negative and close to zero, indicating either no significant impact on the overall growth of the construction land in the TWL region or a weak negative driving effect.

Based on the above, we analyzed the driving factors of the construction land in Tongzhou, Wuqing, and Langfang from 2010-2019. We performed a stepwise regression of the driving factors of the three areas and eliminated the irrelevant variables. The results are shown in Table 6. The $\mathrm{R}^{2}$ of the models are $0.909,0.909$, and 0.975, respectively (Prob > $\mathrm{F}=0.000)$.

Table 6. Estimation results of the driving factors of Tongzhou, Wuqing, and Langfang by stepwise regression (2010-2019).

\begin{tabular}{|c|c|c|c|c|c|c|}
\hline Region & Code & Variable & Coefficient & Standardized Coefficient Beta & $t$ & Significant \\
\hline \multirow[t]{2}{*}{ Tongzhou } & & (constant) & 247.963 & & 54.583 & $0.000 * *$ \\
\hline & X3 & $\begin{array}{l}\text { Investment in fixed } \\
\text { assets }\end{array}$ & 0.579 & 0.959 & 9.546 & $0.000^{* *}$ \\
\hline \multirow[t]{2}{*}{ Wuqing } & & (constant) & 222.783 & & 16.926 & $0.000 * *$ \\
\hline & X5 & $\begin{array}{c}\text { Population of } \\
\text { permanent residents }\end{array}$ & 0.112 & 0.959 & 9.549 & $0.000 * *$ \\
\hline Langfang & X6 & $\begin{array}{c}\text { (constant) } \\
\text { Urbanization rate }\end{array}$ & $\begin{array}{l}586.682 \\
1624.448\end{array}$ & 0.989 & $\begin{array}{l}12.458 \\
18.758\end{array}$ & $\begin{array}{l}0.000 * * \\
0.000 * *\end{array}$ \\
\hline
\end{tabular}

** indicates that the correlation is significant at the 0.01 level.

The regression results show that the main driving factors of construction land in Tongzhou, Wuqing, and Langfang are different; they also differ from the driving factors of the entire TWL region. The construction land area in Tongzhou is mainly affected by fixed asset investment; the construction land area in Wuqing is mainly affected by the permanent resident population; and the construction land area in Langfang is mainly affected by the urbanization rate. The standardized coefficients are all greater than 0.9 , indicating that the three driving factors play an absolute leading role in Tongzhou, Wuqing, and Langfang; the land use pattern in the research area is the comprehensive result of the multi-factor game; and the main driving factors are also different due to the different regions' varying socioeconomic development stages and land management policies. Wuqing is in the outer suburbs of Tianjin but is closer to Beijing than Tianjin Central City. Therefore, the district government's development strategy is inclined to serve Beijing. Langfang also utilizes its proximity to Beijing, and its leading strategy is to meet the development in Beijing by adopting various policies, such as the hukou policy and the preferential policy for buying a house, to attract many migrants to settle down. Both cities have experienced rapid population growth, which has gradually become concentrated in the central urban areas. Due to the increase in the urban population, the demand for houses and jobs has effectively driven the growth of construction land in these two cities. Therefore, the permanent resident population and the urbanization rate have a positive impact on the expansion of the urban construction land. However, Tongzhou New Town has adopted "incremental urban planning," which has expanded the construction scale and continuous building of new areas over the past 10 years to promote the city's development [73]. Therefore, the expansion of the construction land in Tongzhou District has been positively affected by fixed asset investments.

\section{Discussion}

Although the terrain and locations of the TWL's three administrative regions are similar, the LUC has shown great differences over the past 30 years. Tongzhou District and the three northern counties have had the fastest expansion of construction land over the 
past 20 years, showing a significant trend of mutual convergence and even mutual mergers. The development of Wuqing has been relatively slow, with no contiguous development area outside the central city. This has been mainly caused by administrative management and land policy differences. Tongzhou District and the three northern counties were fully guaranteed the construction land index supply from Beijing and Langfang City to construct Tongzhou New Town and North Langfang New Town. To a certain extent, the development of Wuqing has been restricted by the positioning of Tianjin's main agricultural production areas and key ecological protection areas. The problems caused by the differences in the subordination and administrative ranks regarding the coordination of the borderline transboundary regions have also been commonly encountered in the borderline transboundary regions of metropolitan circles worldwide. The urban planning practices in many countries show that although constitutions and laws emphasize the need for local governments to collaborate in areas such as infrastructure, collaborative governance is often challenged by the long-standing reliance on the decision making of central governments; insufficient cooperation between local governments; and power struggles between different levels of government over decision making, funding, and responsibility [74].

The leading factors of the construction land in the TWL region are the changes in the population, economic growth, urban-rural structure, and income level. The main driving factors are the changes in the resident population and the output values of the tertiary and secondary industries. On one hand, determining land demand via population remains the core of the land development policy in the TWL region, which is similar to other regions in China [75]. Furthermore, population-structure prediction and land-demand prediction constitute the core of general land use planning. On the other hand, with economic growth as an assessment-oriented incentive, local governments are motivated to convert more land into commercial land to obtain higher unit outputs; therefore, they increase the amount of construction land [76]. Moreover, fixed asset investments and urbanization rates are the main drivers of some regions. The growth of fixed asset investments improves the capital density of the urban unit land areas and facilitates the expansion of the urban built-up areas [77]. The main driving factors of construction land expansion vary between different administrative regions as a result of the differences in land policies and the management of different administrative bodies.

To better promote local resource integration, the concept of cross-district management and control by means of spatial governance has gradually become the theoretical consensus and practical choice of all involved parties [78]. In recent years, cross-administrative regional planning has been practiced in many countries worldwide to effectively alleviate the resource shortage problem in some cities and promote the transfer of administrative power and resources among cooperative cities. According to the relative strength of political and economic forces on both sides of an administrative boundary, cross-district management can be divided into four modes: strong-weak control, strong-strong control, weak-strong control, and weak-weak control [79]. Due to the existence of Tongzhou District, which is the sub-center of Beijing, the cross-district management represented by the TWL region demonstrates a typical strong-weak control mode. In this mode, the cross-district spatial control of a weak region is led by an economically advantaged region and emphasizes a developed region's cross-district control of an underdeveloped region in terms of the labor commuters and the land and real estate development. Specifically, developed regions pay more attention to the spatial transfer of production factors, such as industry, capital, and technology, while underdeveloped regions pay more attention to the outflow of the labor force. Meanwhile, the developed regions' facilities and service capacities are strengthened, which also shows why the main driving factors of construction land expansion vary among different administrative regions.

Faced with the lack of unified policy-implementation subjects for land management in the TWL region, the Beijing-Tianjin-Hebei Coordinated Development Leading Group has made a series of beneficial attempts to reform cross-district control systems in recent years. Since 2016, the Hebei Provincial Government has made plans for transportation 
and environmental protection in Langfang's three northern counties, as well as other adjacent counties to Beijing, to strengthen their coordination with Beijing's sub-center planning. Moreover, a joint planning review mechanism has been established for the cross-boundary area under the participation of Beijing and Hebei. Under this system, the planning examination and approval power of the three northern counties is concentrated upward and is directly managed by the Hebei Provincial Government in order to effectively solve the problem of the lack of common interest in the coordination subjects caused by the unequal administrative levels of Beijing, Tianjin, and Langfang. Moreover, the "Framework Agreement on Promoting Tong-Wu-Lang Strategic Cooperation and Development (2017)" requires Tongzhou, Wuqing, and Langfang to cooperate in tourism, education, health, and other sectors. However, regarding the implementation of relevant planning in recent years, some practical difficulties remain in managing the coordinated development of the TWL region. Moreover, there is much consensus but not much action [80]. The overall objectives and tasks of the coordination framework are clear but lack specific policy implementation plans, feasible measures, and detailed guidance on the division of the local governments' responsibilities. Meanwhile, great institutional inertia remains in the single hierarchical territorial management system [81]. Many local governments still make relatively independent decisions within their respective jurisdictions, while Tongzhou and Wuqing have made little progress in their coordinated governance attempts. Beijing and Tianjin, the superior governments to which Tongzhou and Wuqing belong, are both powerful governments that are strongly independent, and their awareness of the competition is usually greater than the awareness of cooperation. The concept of protecting local interests still exists; thus, it is difficult to achieve spontaneous coordination in regional development.

\section{Conclusions}

In the cross-boundary regions of metropolitan areas, LUC is a complex system that is affected by the market economy, national policy, population migration, and infrastructure construction, among other factors. This study explores the spatiotemporal LUC in the TWL region from 1990-2020 and analyzes the driving mechanism of the construction land from 2019-2019. The results show that: (1) The construction LUC in the TWL region shows "disordered expansion, rapid expansion, and incremental slowdown", while each administrative region shows different and independent land use characteristics during different periods. From 2010, Tongzhou, Wuqing, and Langfang show a consistent trend of slowing the growth rate of construction land. (2) The driving factors of construction LUC in the TWL region from 2010-2019 are characterized by the interaction of "changes in population, economic growth, the urban-rural structure, and income level", and the comprehensive score of these socioeconomic drivers has increased over the past 10 years. (3) According to the stepwise regression analysis results, the construction land growth in the TWL region is mainly driven by three factors: the permanent resident population, the output value of the tertiary industry, and the output value of the secondary industry. However, the dominant driving factors are different in the different administrative regions; that is, the construction land area in Tongzhou District is mainly affected by fixed asset investment; the construction land area in Wuqing District is mainly affected by the permanent population; and the construction land area in Langfang City is mainly affected by the urbanization rate. This indicates the impact of administrative boundaries on land use development and implies the necessity of strengthening coordinated development.

This study is an attempt to analyze the LUC in cross-boundary regions using remote sensing data in order to show the impact that different administrative subordinations have on land use development. However, some limitations remain. First, due to the limited resolutions of the available remote sensing image data, this study's classification of land use types was relatively rough, and multiple land use types within the construction land could not be further distinguished. The follow-up research should use higher-quality remote sensing data and combine it with other data sources to provide a more detailed 
analysis. Second, this study revealed that the dominant driving forces of the construction land within different administrative regions were different and attempted to explore the associated policy factors. However, the follow-up research should show the correlations between them in a more systematic manner in order to suggest cross-administrative land management in metropolitan areas, which requires urgent attention.

Author Contributions: Conceptualization, L.D.; data curation, Z.Z. and Y.S.; formal analysis, L.D. and Z.Z.; funding acquisition, L.D. and X.R.; investigation, Z.Z. and Y.S.; methodology, L.D. and Z.Z.; project administration, X.R.; software, Z.Z. and Y.S.; validation, L.D. and X.R.; visualization, Z.Z. and Y.S.; writing—original draft, L.D., Z.Z. and X.R.; writing—review and editing, L.D. and X.R. All authors have read and agreed to the published version of the manuscript.

Funding: This research was funded by the National Natural Science Foundation of China (NO. 52078003, NO. 51808330).

Institutional Review Board Statement: Not applicable.

Informed Consent Statement: Not applicable.

Data Availability Statement: Not applicable.

Conflicts of Interest: The authors declare no conflict of interest.

\section{References}

1. Mcdaniel, M.D.; Saha, D.; Dumont, M.G.; Hernandez, M.; Adams, M.A. The effect of land-use change on soil CH4 and N2O fluxes: A global meta-analysis. Ecosystems 2019, 22, 1424-1443. [CrossRef]

2. Kiprotich, P.; Wei, X.; Zhang, Z.; Ngigi, T.; Qiu, F.; Wang, L. Assessing the impact of land use and climate change on surface runoff response using gridded observations and swat+. Hydrology 2021, 8, 48. [CrossRef]

3. Hasan, S.S.; Zhen, L.; Miah, M.G.; Ahamed, T.; Samie, A. Impact of land use change on ecosystem services: A review. Environ. Dev. 2020, 34, 100527. [CrossRef]

4. Newbold, T.; Adams, G.L.; Robles, G.A.; Boakes, E.H.; Ferreira, G.B.; Chapman, A.S.A.; Etard, A.; Gibb, R.; Millard, J.; Outhwaite, C.L.; et al. Climate and land-use change homogenise terrestrial biodiversity, with consequences for ecosystem functioning and human well-being. Emerg. Top. Life Sci. 2019, 3, 207-219. [CrossRef] [PubMed]

5. Kassa, H.; Dondeyne, S.; Poesen, J.; Frankl, A.; Nyssen, J. Transition from forest-based to cereal-based agricultural systems: A review of the drivers of land use change and degradation in southwest Ethiopia. Land Degrad. Dev. 2017, 28, 431-449. [CrossRef]

6. Hoekman, S.K.; Broch, A. Environmental implications of higher ethanol production and use in the us: A literature review. Part ii-biodiversity, land use change, ghg emissions, and sustainability. Renew. Sustain. Energy Rev. 2018, 81, 3159-3177. [CrossRef]

7. Lambin, E.F.; Meyfroidt, P. Global land use change, economic globalization, and the looming land scarcity. Proc. Natl. Acad. Sci. USA 2011, 108, 3465-3472. [CrossRef] [PubMed]

8. Fescenko, A.; Wohlgemuth, T. Spatio-temporal analyses of local biodiversity hotspots reveal the importance of historical land-use dynamics. Biodivers. Conserv. 2017, 26, 2401-2419. [CrossRef]

9. Shi, P.; Zhang, Y.; Li, Z.; Li, P.; Xu, G. Influence of land use and land cover patterns on seasonal water quality at multi-spatial scales. Catena 2017, 151, 182-190. [CrossRef]

10. Veldkamp, A.; Lambin, E.F. Predicting land-use change. Agric. Ecosyst. Environ. 2001, 85, 1-6. [CrossRef]

11. Verburg, P.H.; Eickhout, B.; Van Meijl, H. A multi-scale, multi-model approach for analyzing the future dynamics of European land use. Ann. Reg. Sci. 2008, 42, 57-77. [CrossRef]

12. Chen, Y.; Li, X.; Liu, X.; Zhang, Y.; Huang, M. Quantifying the teleconnections between local consumption and domestic land uses in china. Landsc. Urban Plan. 2019, 187, 60-69. [CrossRef]

13. Liu, J.; Kuang, W.; Zhang, Z.; Xu, X.; Qin, Y.; Ning, J.; Zhou, W.; Zhang, S.; Li, R.; Yan, C.; et al. Spatiotemporal characteristics, patterns, and causes of land-use changes in china since the late 1980s. J. Geogr. Sci. 2014, 24, 195-210. [CrossRef]

14. Meyfroidt, P.; Lambin, E.F.; Erb, K.H.; Hertel, T.W. Globalization of land use: Distant drivers of land change and geographic displacement of land use. Curr. Opin. Environ. Sustain. 2013, 5, 438-444. [CrossRef]

15. Liu, W.; Zhan, J.; Zhao, F.; Yan, H.; Zhang, F.; Wei, X. Impacts of urbanization-induced land-use changes on ecosystem services: A case study of the pearl river delta metropolitan region, china. Ecol. Indic. 2019, 98, 228-238. [CrossRef]

16. Tran, D.X.; Pla, F.; Latorre-carmona, P.; Myint, S.W.; Gaetano, M.; Kieu, H.V. Characterizing the relationship between land use land cover change and land surface temperature. ISPRS J. Photogramm. Remote Sens. 2017, 124, 119-132. [CrossRef]

17. Wang, R.; Derdouri, A.; Murayama, Y. Spatiotemporal simulation of future land use/cover change scenarios in the Tokyo metropolitan area. Sustainability 2018, 10, 2056. [CrossRef]

18. Aguilera, F.; Valenzuela, L.M.; Botequilha-Leitao, A. Landscape metrics in the analysis of urban land use patterns: A case study in a Spanish metropolitan area. Landsc. Urban Plan. 2011, 99, 226-238. [CrossRef] 
19. Gong, J.; Hu, Z.; Chen, W.; Liu, Y.; Wang, J. Urban expansion dynamics and modes in metropolitan Guangzhou, china. Land Use Policy 2018, 72, 100-109. [CrossRef]

20. Pan, H.; Tong, X.; Xu, X.; Luo, X.; Jin, Y.; Xie, H.; Li, B. Updating of land cover maps and change analysis using globeland30 product: A case study in shanghai metropolitan area, china. Remote Sens. 2020, 12, 3147. [CrossRef]

21. $\mathrm{Wu}$, J.; Jenerette, G.D.; Buyantuyev, A.; Redman, C.L. Quantifying spatiotemporal patterns of urbanization: The case of the two fastest growing metropolitan regions in the united states. Ecol. Complex. 2011, 8, 1-8. [CrossRef]

22. Dadashpoor, H.; Azizi, P.; Moghadasi, M. Land use change, urbanization, and change in landscape pattern in a metropolitan area. Sci. Total Environ. 2019, 655, 707-719. [CrossRef] [PubMed]

23. Osman, T.; Divigalpitiya, P.; Arima, T. Driving factors of urban sprawl in Giza governorate of Greater Cairo Metropolitan Region using AHP method. Land Use Policy 2016, 58, 21-31. [CrossRef]

24. Zeng, C.; Liu, Y.; Stein, A.; Jiao, L. Characterization and spatial modeling of urban sprawl in the Wuhan metropolitan area, china. Int. J. Appl. Earth Obs. Geoinf. 2015, 34, 10-24. [CrossRef]

25. Kong, F.; Yin, H.; James, P.; Hutyra, L.R.; He, H.S. Effects of spatial pattern of greenspace on urban cooling in a large metropolitan area of eastern china. Landsc. Urban Plan. 2014, 128, 35-47. [CrossRef]

26. $\mathrm{Wu}, \mathrm{K} . ; \mathrm{Ye}, \mathrm{X} . ; \mathrm{Qi}, \mathrm{Z} . ; \mathrm{Zhang}, \mathrm{H}$. Impacts of land use/land cover change and socioeconomic development on regional ecosystem services: The case of fast-growing Hangzhou metropolitan area, china. Cities 2013, 31, 276-284. [CrossRef]

27. Ye, Y.; Bryan, B.A.; Zhang, J.E.; Connor, J.D.; Chen, L.; Qin, Z.; He, M. Changes in land-use and ecosystem services in the Guangzhou-Foshan metropolitan area, china from 1990 to 2010: Implications for sustainability under rapid urbanization. Ecol. Indic. 2018, 93, 930-941. [CrossRef]

28. Bose, A.; Chowdhury, I.R. Monitoring and modeling of spatio-temporal urban expansion and land-use/land-cover change using markov chain model: A case study in Siliguri Metropolitan Area, West Bengal, India. Model. Earth Syst. Environ. 2020, 6 , 2235-2249. [CrossRef]

29. Jun, M. A comparison of a gradient boosting decision tree, random forests, and artificial neural networks to model urban land use changes: The case of the Seoul metropolitan area. Int. J. Geogr. Inf. Sci. 2021, 35, 2149-2167. [CrossRef]

30. Rahnama, M.R. Forecasting land-use changes in Mashhad Metropolitan area using cellular automata and markov chain model for 2016-2030. Sustain. Cities Soc. 2021, 64, 102548. [CrossRef]

31. Sohn, C.; Reitel, B.; Walther, O. Cross-border metropolitan integration in Europe: The case of Luxembourg, Basel, and Geneva. Environ. Plan. C-Gov. Policy 2009, 27, 922-939. [CrossRef]

32. Vandenberg, L.; Braun, E.; Vandermeer, J. The organising capacity of metropolitan regions. Environ. Plan. C-Gov. Policy 1997, 15, 253-272. [CrossRef]

33. Chen, L.; Xu, L.; Yang, Z. Inequality of industrial carbon emissions of the urban agglomeration and its peripheral cities: A case in the pearl river delta, china. Renew. Sustain. Energy Rev. 2019, 109, 438-447. [CrossRef]

34. Chen, Y.; Sun, B. Does "agglomeration shadow" exist in Beijing-Tianjin-Hebei region? Large cities' impact on regional economic growth. Geogr. Res. 2017, 36, 1936-1946.

35. Giannotti, M.; Barros, J.; Tomasiello, D.B.; Smith, D.; Pizzol, B.; Santos, B.M.; Zhong, C.; Shen, Y.; Marques, E.; Batty, M. Inequalities in transit accessibility: Contributions from a comparative study between global south and north metropolitan regions. Cities 2021, 109, 103016. [CrossRef]

36. Han, H.; Yang, C.; Wang, E.; Song, J.; Zhang, M. Evolution of jobs-housing spatial relationship in Beijing metropolitan area: A job accessibility perspective. Chin. Geogr. Sci. 2015, 25, 375-388. [CrossRef]

37. Peng, J.; Tian, L.; Liu, Y.; Zhao, M.; Hu, Y.N.; Wu, J. Ecosystem services response to urbanization in metropolitan areas: Thresholds identification. Sci. Total Environ. 2017, 607, 706-714. [CrossRef]

38. Vicuna, M.; Orellana, A.; Truffello, R.; Moreno, D. Urban integration and quality of urban life: Dilemmas in metropolitan contexts. Rev. INVI 2019, 34, 17-47.

39. Cho, J.; Kim, J.H.; Kim, Y. Metropolitan governance structure and growth-inequality dynamics in the united states. Environ. Plan. A-Econ. Space 2019, 51, 598-616. [CrossRef]

40. Lin, G.C.S.; Zhang, A.Y. China's metropolises in transformation: Neoliberalizing politics, land commodification, and uneven development in beijing. Urban Geogr. 2017, 38, 643-665. [CrossRef]

41. Ávila Sánchez, H. Agricultura urbana y periurbana: Reconfiguraciones territoriales y potencialidades en torno a los sistemas alimentarios urbanos. Investig. Geográficas 2019, 98, 9. [CrossRef]

42. Bao, W.; Yang, Y.; Zou, L. How to reconcile land use conflicts in mega urban agglomeration? A scenario-based study in the Beijing-Tianjin-Hebei region, china. J. Environ. Manag. 2021, 296, 113168. [CrossRef]

43. Ma, W.; Jiang, G.; Chen, Y.; Qu, Y.; Zhou, T.; Li, W. How feasible is regional integration for reconciling land use conflicts across the urban-rural interface? Evidence from Beijing-Tianjin-Hebei metropolitan region in china. Land Use Policy 2020, $92,104433$. [CrossRef]

44. Sukhwani, V.; Thapa, K.; Shaw, R.; Deshkar, S.; Mitra, B.K.; Yan, W. Addressing urban-rural water conflicts in Nagpur through benefit sharing. Water 2020, 12, 2979. [CrossRef]

45. Bittencourt, T.A.; Giannotti, M.; Marques, E. Cumulative (and self-reinforcing) spatial inequalities: Interactions between accessibility and segregation in four Brazilian metropolises. Environ. Plan. B-Urban Anal. City Sci. 2021, 48, 1989-2005. [CrossRef] 
46. Blanco, J.; Apaolaza, R. Socio-territorial inequality and differential mobility. Three key issues in the Buenos Aires Metropolitan Region. J. Transp. Geogr. 2018, 67, 76-84. [CrossRef]

47. Dutta, I.; Das, A. Exploring the dynamics of spatial inequality through the development of sub-city typologies in english bazar urban agglomeration and its peri urban areas. GeoJournal 2019, 84, 829-849. [CrossRef]

48. Musterd, S.; Hochstenbach, C.; Boterman, W. Ripples of structural economic transformation: The changing social geographies of dutch metropolitan regions. Appl. Geogr. 2020, 116, 102151. [CrossRef]

49. Dupont, V. Conflicting stakes and governance in the peripheries of large Indian metropolises-an introduction. Cities 2007, 24, 89-94. [CrossRef]

50. Florida, R.; Adler, P. The patchwork metropolis: The morphology of the divided postindustrial city. J. Urban Aff. 2018, 40, 609-624. [CrossRef]

51. Savitch, H.V.; Adhikari, S. Fragmented regionalism: Why metropolitan America continues to splinter. Urban Aff. Rev. 2017, 53, 381-402. [CrossRef]

52. Durand, F.; Decoville, A.; Knippschild, R. Everything all right at the internal eu borders? The ambivalent effects of cross-border integration and the rise of Euroscepticism. Geopolitics 2020, 25, 587-608. [CrossRef]

53. Gumy, A.; Drevon, G.; Kaufmann, V. Inequalities in access to cross-border resources? An analysis based on spatio-temporal behaviours in the cross-border area of Greater Geneva. Eur. Urban Reg. Stud. 2022, 29, 85-106. [CrossRef]

54. Roeder, A.; Proepper, M.; Stellmes, M.; Schneibel, A.; Hill, J. Assessing urban growth and rural land use transformations in a cross-border situation in Northern Namibia and Southern Angola. Land Use Policy 2015, 42, 340-354. [CrossRef]

55. Castanho, R.A. The relevance of political engagement and transparency in cross-border cooperation (CBC) environments: Analyzing border cities in Europe. Lex Localis-J. Local Self-Gov. 2020, 18, 487-502. [CrossRef]

56. Oliveras González, X. Iniciativas de planificación territorial transfronteriza en Matamoros-Brownsville (México-Estados Unidos). Investig. Geográficas 2016, 2016, 154-167. [CrossRef]

57. Ulrich, P. Territorial cooperation, supraregionalist institution-building and national boundaries: The European grouping of territorial cooperation (EGTC) at the eastern and western German borders. Eur. Plan. Stud. 2020, 28, 57-80. [CrossRef]

58. Yang, C. Multilevel governance in the cross-boundary region of Hong Kong-pearl river delta, China. Environ. Plan. A-Econ. Space 2005, 37, 2147-2168. [CrossRef]

59. You, N.; Shen, Z.; Pai, J.; Kobayashi, F. Prospects for sub-regional cooperation in Fujian and Taiwan from perspective of urban planning system: A case study of Pingtan experimental area. Int. Rev. Spat. Plan. Sustain. Dev. 2017, 5, 60-79. [CrossRef]

60. Zhao, C.; Jensen, J.; Zhan, B. A comparison of urban growth and their influencing factors of two border cities: Laredo in the US and Nuevo Laredo in Mexico. Appl. Geogr. 2017, 79, 223-234. [CrossRef]

61. Li, G.; Song, C. Research on interregional regulation in the border of Beijing-Tianjin-Hebei metropolitan region: A case study of Tongzhou-Wuqing-Langfang. Reg. Econ. Rev. 2017, 1, 52-59. [CrossRef]

62. Alipbeki, O.; Alipbekova, C.; Sterenharz, A.; Toleubekova, Z.; Aliyev, M.; Mineyev, N.; Amangaliyev, K. A spatiotemporal assessment of land use and land cover changes in peri-urban areas: A case study of Arshaly District, Kazakhstan. Sustainability 2020, 12, 1556. [CrossRef]

63. Li, K.M.; Feng, M.M.; Biswas, A.; Su, H.H.; Niu, Y.L.; Cao, J.J. Driving factors and future prediction of land use and cover change based on satellite remote sensing data by the LCM model: A case study from Gansu province, china. Sensors 2020, $20,2757$. [CrossRef]

64. Alijani, Z.; Hosseinali, F.; Biswas, A. Spatio-temporal evolution of agricultural land use change drivers: A case study from Chalous region, Iran. J. Environ. Manag. 2020, 262, 13. [CrossRef] [PubMed]

65. Zhou, Y.; Li, X.H.; Liu, Y.S. Land use change and driving factors in rural china during the period 1995-2015. Land Use Policy 2020, 99, 16. [CrossRef]

66. Jiao, L.; Li, Z.; Xu, G.; Zhang, B.; Dong, T.; Gu, Y. The characteristics and patterns of spatially aggregated elements in urban areas of Wuhan. Acta Geogr. Sin. 2017, 72, 1432-1443.

67. Zhang, J. Characteristics and driving factors of land use change in Beijing-Tianjin-Hebei region. Contemp. Econ. 2019, 7, 54-57.

68. Li, C.; Wu, K.; Zha, L. Research on land use change characteristics and driving forces in Beijing, Tianjin and Hebei region. China Popul. Resour. Environ. 2016, 26, 252-255. [CrossRef] [PubMed]

69. Lin, J. Urban-Rural Construction Land Growth in China; The Commercial Press: Beijing, China, 2009.

70. Xia, F.; Li, Y.; Yan, J. The relationship between land finance and economic growth under the industrial structure perspective-based on dynamic panel data analysis with SYS-GMM methods. Econ. Geogr. 2014, 34, 85-92. [CrossRef]

71. Guo, Z.; Gu, N. Institutional change, land finance and extended urban expansion: A new perspective to explain the phenomenon of urbanization and high industrial structure in China. Soc. Sci. Res. 2013, 1, 8-14.

72. Dong, L.; Lin, J. The Thinking and Exploring of Integrated Land-Use Planning; China Architecture \& Building Press: Beijing, China, 2010.

73. Zhang, J.; Wang, S. Land consolidation strategies of collective construction land in the background of "less amount and improving quality" in Tongzhou District, Beijing. Planners 2015, 31, 29-35.

74. Leck, H.; Simon, D. Local authority responses to climate change in South Africa: The challenges of transboundary governance. Sustainability 2018, 10, 2542. [CrossRef] 
75. Chen, X. The logical identification of "population orient land" planning method triggered by the tightening amount of construction land: Taking Hangzhou' main district as an example. In Proceedings of the 2021 China Urban Planning Annual Conference, Chengdu, China, 25-30 September 2021; pp. 321-328.

76. Piao, Y.; Ma, K. Economic driving force of urban built-up area expansion in Beijing: 1978-2002. Nat. Resour. Econ. China 2006, 7, 34-37.

77. Li, X. The Fixed Assets Investment of Lanzhou and the Relation between Itself and the Spatial Expansion of City; Lanzhou University: Lanzhou, China, 2007.

78. Deng, Y. Self-organization characteristics of urban extension and the planning effect evaluation: A case study of Beijing. Geogr. Res. 2016, 35, 353-362.

79. Liu, H.; Ma, L. Space governances in Beijing-Tianjin-Hebei border region. Areal Res. Dev. 2020, 39, 36-40.

80. Liu, F.; Fu, L.; Xu, K. Structure and effect measurement of inter-government and inter-city cooperation network of medical and health services: Taking Beijing-Tianjin-Hebei metropolitan region as an example. J. Northeast. Univ. (Soc. Sci. ) 2021, 23, 59-66. [CrossRef]

81. $\mathrm{Hu}, \mathrm{Y}$. Difficulties of air pollution cooperative governance in Beijing-Tianjin-Hebei region and the solution paths: Relation network, action strategy and governance structure. J. Dalian Univ. Technol. (Soc. Sci.) 2020, 41, 48-56. [CrossRef] 